\title{
European rheumatology is advancing
}

\author{
Tore K Kvien, Ferdinand C Breedveld and Josef S Smolen
}

EULAR (European League Against Rheumatism) is the partnership organization of scientific rheumatology societies from 43 European countries and 30 national patient organizations. Its key objectives are to foster research and to support and organize educational activities that help improve prevention and treatment of rheumatic diseases and rehabilitation of patients.

Educational and research activities are organized by the seven Standing Committees (Clinical Studies, Investigative Rheumatology, Paediatric Rheumatology, Epidemiology, Education, Social Leagues, and Allied Health Professionals). One particularly successful activity has been the provision of guidance to working groups for the development of recommendations (Dougados $\mathrm{M}$ et al. [2004] Ann Rheum Dis 63: 1172-1176), which so far have covered the management of ankylosing spondylitis (Zochling J et al. [2006] Ann Rheum Dis 65: 442-452), early arthritis (Combe B et al. [2006] Ann Rheum Dis [doi: 10.1136/ard.2005.044354]), and gout (W Zhang, personal communication). At the EULAR congress in June, recommendations for management will be presented for hand osteoarthritis, fibromyalgia and systemic lupus erythematosus. In addition, recommendations for conducting clinical trials in systemic lupus erythematosus and systemic vasculitis will be presented. Importantly, EULAR and the American College of Rheumatology are currently developing task forces comprising experts from both organizations; these task forces will develop joint recommendations in specific areas of rheumatology.

Other prominent activities include the establishment of high-standard networks of Centers of Excellence in rheumatology research, the provision of competitive research grants to collaborative projects in Europe, and the donation of bursaries to visiting research fellows.

EULAR aims to influence political processes to improve the awareness and priority level of rheumatic diseases in Europe. The Alliance Against Arthritis was established in 2004 as a campaigning arm of EULAR. Rheumatic ....international collaboration ... gives hope for progress in global strategies to improve... prevention and treatment of rheumatic diseases

TK Kvien is president of EULAR, FC Breedveld is the president elect, and JS Smolen is the immediate past president.

\section{Competing interests}

The authors declared they have no competing interests.

www.nature.com/clinicalpractice doi:10.1038/ncprheum0213 diseases are not an explicit priority in the current research framework program of the European Union. An important step in the right direction was the approval of a written declaration, which was signed by the majority of the members of the European Parliament. This declaration, which was adopted in October 2005, calls on the Commission and Council to prioritize rheumatic diseases in health care and research, and to strengthen disability legislation.

EULAR is also working with the European regional office of the $\mathrm{WHO}$ to ensure that rheumatic diseases will be part of both the European Strategy on Noncommunicable Diseases and the future program on counteracting obesity, which is of particular relevance in osteoarthritis.

The next major activity of EULAR is the Annual Congress in Amsterdam, The Netherlands, 21-24 June 2006. Last year's Congress attracted nearly 10,000 participants from 99 countries, with more people than usual from outside Europe, including the US. The number of scientific abstracts submitted this year approached 3,000 (an increase of $20 \%$ compared with last year). We are also aware that the latest American College of Rheumatology/Association of Rheumatology Health Professionals Annual Scientific Meeting had a larger attendance than ever.

This worldwide growth in the profile of rheumatology reflects the advances that have been achieved over the past few years, such as improvements in our understanding of pathophysiological processes, and the development of new imaging tools and drugs, and better treatment strategies. These achievements also call for a global strategy, which has to take into account, among other factors, that many patients do not have access to these new opportunities. The increasing international collaboration between rheumatology organization gives hope for progress in global strategies to improve the prevention and treatment of rheumatic diseases.

Supplementary information is available on the Nature Clinical Practice Rheumatology website. 